\title{
Mechanical Properties of Friction Stir-Welded Joints of Aluminum Alloys
}

\author{
W. J. Chen, ${ }^{\mathrm{a}, \mathrm{b}, 1}$ H. Chen, ${ }^{\mathrm{a}}$ and B. X. Wu ${ }^{\mathrm{c}}$ \\ ${ }^{a}$ School of Materials Science and Engineering, Southwest Jiaotong University, Chengdu, Sichuan, \\ China \\ b School of Materials Science and Engineering, Xihua University, Chengdu, Sichuan, China. \\ ${ }^{c}$ CAIC Electronics Co Ltd, Chengdu, Sichuan, China \\ ${ }^{1}$ njchenwenjing@163.com
}

Mechanical properties, intergranular corrosion, and a chemical composition of the welded joint, produced with friction stir welding of a 6061 T651 aluminum alloy were investigated. The results show that the welded seam is uniform, with a smooth surface. There are no deformation and defects, such as cracks or gas-filled porosity. The average tensile strength of welded joints is $73 \%$ of that of the base material, while the average yield strength and elongation are only 54\% and 43\% of those of the base material. After intergranular corrosion, microhardness changes evidently and corrosion resistance is lower in the root of the weld nugget zone. The change in microhardness is not pronounced in the weld nugget zone and welded surface, but the change in microhardness is well-pronounced and corrosion resistance is lower in the thermomechanically-and heat-affected zones.

Keywords: 6061T651 Al-alloy, welded joint, mechanical property, intergranular corrosion.

Introduction. Due to moderate strength, excellent corrosion resistance, low tendency to stress corrosion cracking and good formability, 6061T651 aluminum alloy, which belongs to $\mathrm{Al}-\mathrm{Mg}-\mathrm{Si}$ aluminum alloys, is widely used in the modern construction, transportation, aerospace, military manufacturing, and power electronics.

Friction stir welding (FSW) is rapidly developed worldwide and applied to aerospace, high-speed buses, shipbuilding, bridge construction et. al. Initially, the FSW technique was used for low melting point alloys, such as Al alloys, but recently FSW has been used for $\mathrm{Cu}, \mathrm{Mg}$, and Ti alloys, and even for steels. As compared to the standard welding, FSW is a more stable process, which provides a good forged and fine-grain structure in the weld without defects such as pores, cracks, slag and so on. A single-pass weld with thickness of $0.4 \sim 100 \mathrm{~mm}$ and multiple joints can be achieved by FSW without application of filler metals and protective gas in the welding process [1-3]. Mechanical properties and intergranular corrosion behavior of friction stir welding joints in $6061 \mathrm{~T} 651$ aluminum alloy have been investigated.

1. Experimental.

1.1. Materials and Welding Parameters. Friction stir welding experiments were conducted on $6061 \mathrm{~T} 651$ alloy specimens with dimensions of $200 \times 100 \times 6 \mathrm{~mm}$. The chemical composition of the alloy is given in Table 1 . The specimens were thoroughly degreased with acetone and dried in air. Welding run-off tab was added in welding. The adjustable welding tool used has a scrolled shoulder with a diameter of $9.50 \mathrm{~mm}$ and the right-hand threaded pin with a diameter of $3.175 \mathrm{~mm}$. Friction stir welding speed was 95 $\mathrm{mm} / \mathrm{min}$ and rotation speed was $900 \mathrm{rpm}$.

1.2. Tensile Tests. Tensile tests were carried out on welding joints with no heat treatment. The geometry and dimensions of tensile specimens is shown in Fig. 1.

1.3. Intergranular Corrosion. According to GB7998-87 intergranular corrosion standard for aluminum alloys, intergranular corrosion tests were conducted on welding joints with dimensions of $40 \times 25 \mathrm{~mm}$. They were thoroughly degreased with ethanol and 
$\mathrm{T}$ a $\mathrm{b} 1 \mathrm{e} 1$

Chemical Composition of the Base Metal (wt.\%)

\begin{tabular}{|c|c|c|c|c|c|c|c|c|c||}
\hline Element & $\mathrm{Mg}$ & $\mathrm{Mn}$ & $\mathrm{Fe}$ & $\mathrm{Si}$ & $\mathrm{Cr}$ & $\mathrm{Cu}$ & $\mathrm{Zn}$ & $\mathrm{Ti}$ & $\mathrm{Al}$ \\
\hline wt.\% & 0.90 & 0.12 & 0.40 & 0.67 & 0.16 & 0.25 & 0.25 & 0.05 & Others \\
\hline
\end{tabular}

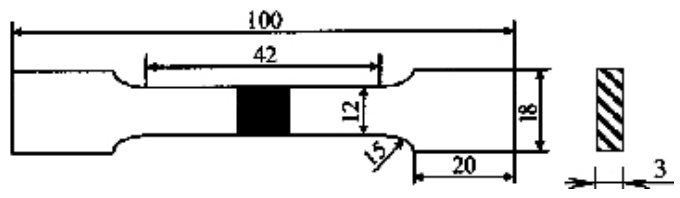

Fig. 1. Dimensions of the tensile test specimen.

held in $10 \%$ sodium hydroxide for $15 \mathrm{~min}$. Etching solution was the mixture of $57 \mathrm{~g}$ sodium chloride, $1000 \mathrm{ml}$ water and $10 \mathrm{ml}$ hydrochloric acid. Intergranular corrosion specimens were placed into the etching solution, held for $12 \mathrm{~h}$ at $(35 \pm 2)^{\circ} \mathrm{C}$ and investigated by optical microscope (OM).

\section{Results and Discussion.}

2.1. Macroscopic Morphology. A macroscopic view of the cross section of the welded joint is shown in Fig. 2. The weld is smooth and uniform, with no pronounced deformations, pores, cracks, or fusion defects. A small amount of wavy burr is observed.

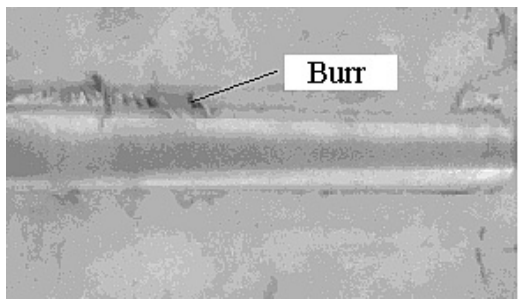

Fig. 2. Morphologies of welded joints.

2.2. Tensile Properties. Tensile properties are shown in Table 2, which designations 1-1 and 1-2 correspond to the welded joints, while 1-3 and 1-4 to the base metals. Tensile strength values of welded joints and base metals are about 300 and $410 \mathrm{MPa}$, respectively. The average tensile strength of welded joints is $73 \%$ of that of the base material, while the average yield strength and elongation rate of welded joints are only 54 and $43 \%$ of the respective values of the base material, as is shown in Table 2. The fracture sites and patterns of specimens 1-1 and 1-2 are similar: the fracture site is a heat-affected zone (HAZ) and fracture pattern is $45^{\circ}$ shear fracture with a fine microstructure. Therefore, HAZ is the weakest link of FSW welded joints.

$\mathrm{T}$ a b 1 e 2

Tensile Test Results

\begin{tabular}{||c|c|c|c||}
\hline No. & Tensile strength (MPa) & Yield strength (MPa) & Elongation rate (\%) \\
\hline $1-1$ & 315 & 210 & 5.4 \\
\hline $1-2$ & 285 & 161 & 4.8 \\
\hline $1-3$ & 415 & 340 & 12.2 \\
\hline $1-4$ & 405 & 370 & 11.2 \\
\hline
\end{tabular}


The above results can be attributed to the following two factors: the first one is dissolving of the aging precipitation with the increase in temperature in the welded joint, which results in the joint strength reduction. The second one is stress concentration in the transition zone of FSW tool shoulder and base metal, insofar as the welded joint is thinner than the base metal. Furthermore, the stir tool tilts to 2 degree towards the welding direction, which generates compression in the metal of the stir tool front side and tension in the its back side during stir tool rotation. This results in nonuniform distribution of the welded metal between stir tool sides, so that its front part becomes thinner than that of the back one. Therefore, the highest stress concentration is observed in the front section [1-3], while fracture occurs in the HAZ.

The fracture morphology of tensile tests is investigated with scanning electron microscopy (SEM), which is illustrated by Fig. 3. The specimens have a high ductility at room temperature. Fiber area and shear lips are seen in the fracture center. Fine circular equiaxed dimples are observed, as well as few traces of the tongue cleavage fracture, whereas the cleavage pattern is quite evident.

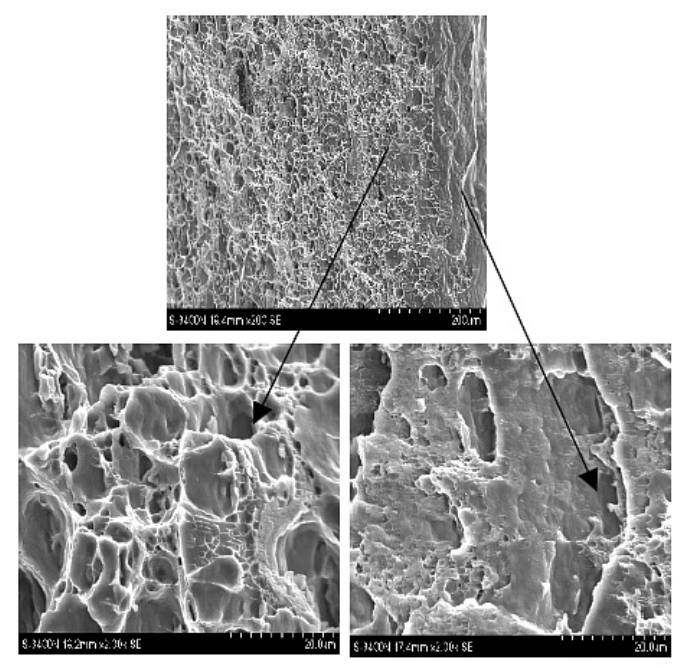

Fig. 3. SEM morphology of tensile fracture.

2.3. Component Analysis. Energy-dispersive X-ray spectroscopy (EDS) test was conducted for analyzing the distribution of chemical elements in the cross section of welded joint and longitudinal section of welding nugget zones, which are shown in Fig. 4. The contents of $\mathrm{Mg}$ and Si hardly in the cross section remain unchanged, while the content of Al exhibits only a slight variation, as compared to the base metal. This is quite self-evident, since the metal volume in the welded joint remains unchanged during the FSW process: an extrusion cavity is formed among FSW tool shoulder, probe and non-melted base metal, where the metal plastic flow occurs. In addition to pressure and friction induced by the rotational motion of the FSW tool shoulder, the welded metal is subjected to friction of the rotational motion and shear force from the FSW tool head. Therefore, the metal grains become elongated and broken in the thermomechanical stirring. The material becomes superplastic, and the metal of the front side is squeezed into the back one. With higher deformations, grains of the base metal become elongated, and further recovery and dynamic recrystallization occur in the broken grains. Since the FSW is characterized by relatively low temperature, intense plastic deformation, rapid cooling of welded joint and HAZ and mechanical agitation of the stir tool, these factors override the negative effects of the element loss and nonuniform distribution of fusion welding in the welding nugget zones. 

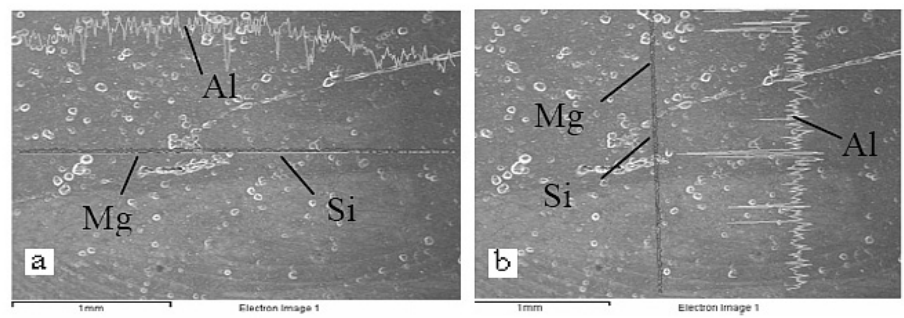

Fig. 4. EDS test profile of welded joint: (a) welded joint; (b) welding nugget zones.

2.4. Intergranular Corrosion Analysis. The corrosion resistance of welded joint in 6061T651 alloys is tested according to the GB7998-87 standard. An intensive gas release in the welding nugget zones was observed, when the specimens were immersed into $\mathrm{NaCl}$ solution, and the surface was etched severely. However, the number of cavities, which appeared in the base metal, was quite small.

The microstructure of intergranular corrosion in the base metal, thermomechanically affected zones (TMAZ) and welding nugget zones is shown in Fig. 5. The intergranular corrosion of TMAZ and welding nugget zones is quite intensive, and cracking is observed after etching in the welding zone. The reason is that the friction-induced heat release between the FSW tool head and workpiece implies intense plastic deformation and recrystallization with stirring and braking in the welding nugget zones. Hence, onion circle microstructure is formed by plastic flow in the fusion zone with fine grains and equiaxed grains appearing in its center due to partial melting. A pronounced plastic deformation and partial recrystallization occur in TMAZ and HAZ. Furthermore, grains grow and become coarse due to rotation of the FSW machine and heat release of the metal flow. So the microstructure becomes more coarse than that of the welding nugget zones $[5,6]$. Therefore, a intense intergranular corrosion occurs in the welding zone and HAZ.

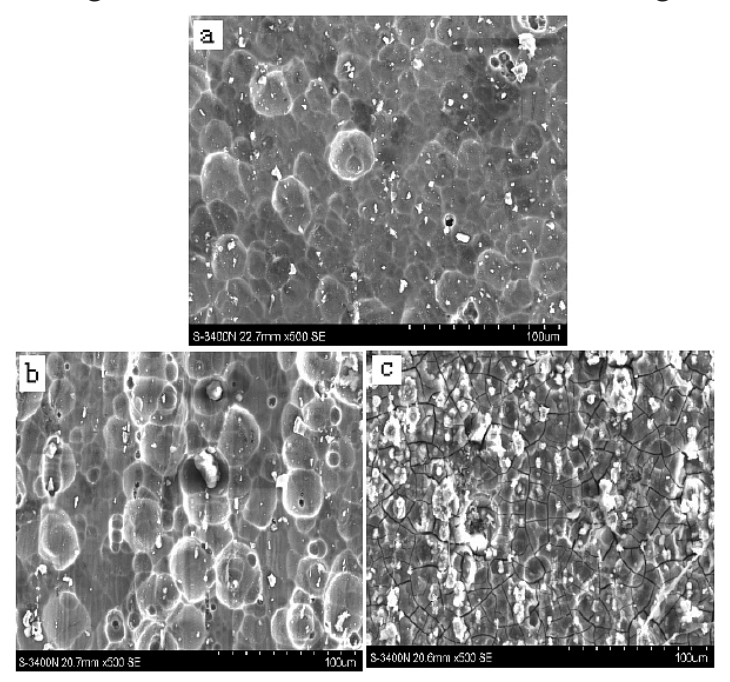

Fig. 5. Microstructure of welded joint after intercrystalline corrosion: (a) parent metal; (b) TMAZ; (c) weld nugget zone.

2.5. Microhardness Evaluation. The test of mechanical properties before and after corrosion tests is used to evaluate the partial corrosion effect [6]. Since hardness can indicate the deformation resistance of metals, hardness variation in welded joints can reflect the mechanical properties of welded joints. 
The microhardness of welded joints before and after intergranular corrosion testing is measured from the surface of welding nugget zone to the root zone and from base metal to welding nugget zone using an HVS-1000 Vickers hardness tester with $1.96 \mathrm{~N}$ load. The details of microhardness measurement are shown in Fig. 6.

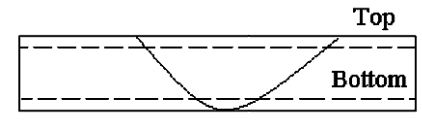

Fig. 6. Measurement direction in the microhardness test.

Figure 7a shows microhardness of the welded joint root before and after intergranular corrosion testing. Variation of microhardness of the welded joint root is high, and its value after corrosion testing is lower than before. However, microhardness of the base metal before and after corrosion testing changes only slightly. This can be attributed to the fact that grains of the welded zone are finer than those of the base metal due to recrystallization of the welding nugget zone and, thus, intergranular corrosion resistance of the welded zone is weaker than that of the base metal.

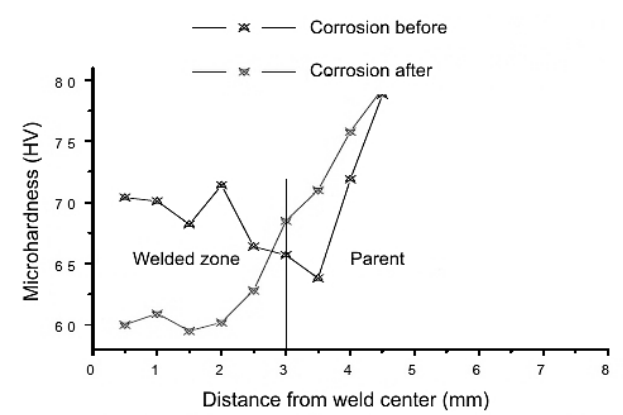

a

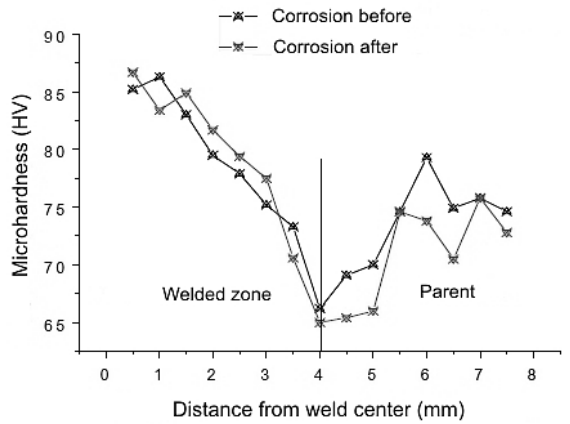

b

Fig. 7. Microhardness profile of welded joint root (a) and welded joint surface (b).

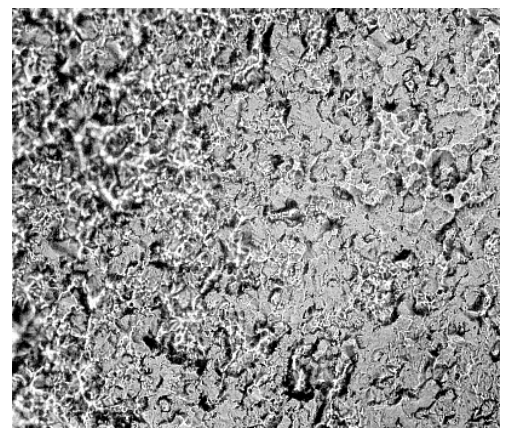

Fig. 8. Microstructure of TMAZ.

Microhardness of the welded joint surface before and after intergranular corrosion testing is shown in Fig. 7b: although the microhardness variation in TMAZ and HAZ before and after corrosion testing is high, in the welded zone it is quite low. Grains near the welding nugget zones undergo a dynamic recrystallization and turn into equiaxed grains due to the mechanical stirring and thermal cycling in TMAZ and HAZ during the welding process, while the growth of grains, which are located far from the welding nugget zone, is 
affected only by thermal cycling. Therefore, the size and morphology of grains in TMAZ and HAZ are not uniform: in addition to equiaxed grains, there are also elongated band structures, as shown in Fig. 8. Hence, the microhardness before and after corrosion testing changes quite sharply.

\section{Conclusions}

1. The friction stir welding of a $6061 \mathrm{~T} 651$ aluminum alloy was conducted with 95 $\mathrm{mm} / \mathrm{min}$ welding speed and $900 \mathrm{rpm}$ rotation speed. The weld is smooth, and the welded joint is uniform without pronounced deformation, pores, cracks, any fusion defects, etc. A small amount of wavy burr exists.

2. The average tensile strength of the welded joints is $73 \%$ of the base material, which reaches to $300 \mathrm{MPa}$, while their average yield strength and elongation rate are only 54 and $43 \%$ of the base material, being $185 \mathrm{MPa}$ and $5.1 \%$, respectively.

3. Microhardness variation of the welded joint root is high, and their corrosion resistance is low. The minimal value of microhardness in the weld joint after corrosion testing is $60 \mathrm{HV}$.

4. In the surface of the welded joints, the microhardness variation in TMAZ and HAZ before and after corrosion testing is high, while in the welding nugget zone and the base metal it is quite low.

Acknowledgments. This study was supported by Sichuan Provincial Department of Education Project (11ZA006) and the Open Research Subject of Key Laboratory (Research Base) of Xihua University (szjj2014-060).

1. H. Zhang, S. B. Lin, L. Wu, et al., "Microstructure of friction stir welds in AZ31 magnesium alloy," The Chinese J. Nonferr. Metals, 13, No. 6, 1510-1513 (2003).

2. D. M. Rodrigues, A. Loureiro, C. Leitao, et al., "Influence of friction stir welding parameters on the microstructural and mechanical properties of AA 6016-T4 thin welds," Mater. Design, 30, 1913-1920 (2009).

3. P. Cavaliere, R. Nobile, F. W. Panella, and A. Squillace, "Mechanical and microstructural behaviour of 2024-7075 aluminium alloy sheets joined by friction stir welding," Int. J. Mach. Tools Manuf., 46, 588-594 (2006).

4. Y. L. Wang and H. Chen, in: Ben She Yi Ming (Ed.), Welding Technology for High-Speed Trains Aluminum Alloy Bodywork [Chinese edition], Southwest Jiaotong University Press (2012), pp. 65-80.

5. G. Barcellona, G. Buffa, L. Fratini, and D. Palmeri, "On microstructural phenomena occurring in friction stir welding of aluminium alloys," J. Mater. Process. Technol., 177, 340-343 (2006).

6. Y. S. Sato, P. Arkom, H. Kokawa, et al., "Effect of microstructure on properties of friction stir welded Inconel Alloy 600," Mater. Sci. Eng. A, 477, 250-258 (2008).

Received 20. 10. 2014 